\title{
Unique mutation portraits and frequent COL2Al gene alteration in chondrosarcoma
}

\author{
Yasushi Totoki, ${ }^{1}$ Akihiko Yoshida, ${ }^{2}$ Fumie Hosoda, ${ }^{1}$ Hiromi Nakamura, ${ }^{1}$ Natsuko Hama, ${ }^{1}$ \\ Koichi Ogura, ${ }^{3}$ Aki Yoshida, ${ }^{4}$ Tomohiro Fujiwara, ${ }^{3}$ Yasuhito Arai, ${ }^{1}$ Junya Toguchida, ${ }^{5}$ \\ Hitoshi Tsuda, ${ }^{2}$ Satoru Miyano, ${ }^{6}$ Akira Kawai, ${ }^{3}$ and Tatsuhiro Shibata ${ }^{1}$ \\ ${ }^{1}$ Division of Cancer Genomics, National Cancer Center Research Institute, Chuo-ku, Tokyo, 104-0045, Japan; ${ }^{2}$ Division of Pathology \\ and Clinical Laboratories, ${ }^{3}$ Division of Musculoskeletal Oncology, National Cancer Center Hospital, Chuo-ku, Tokyo, 104-0045, Japan; \\ ${ }^{4}$ Department of Orthopaedic Surgery, Okayama University Graduate School of Medicine, Dentistry and Pharmaceutical Sciences, \\ Okayama, 700-8558, Japan; ${ }^{5}$ Department of Tissue Regeneration, Institute for Frontier Medical Sciences, Kyoto University, Kyoto, \\ 606-8507, Japan; ${ }^{6}$ Laboratory of DNA Informatics Analysis, Human Genome Center, The Institute of Medical Science, The University \\ of Tokyo, Minato-ku, Tokyo, 108-8639, Japan
}

\begin{abstract}
Chondrosarcoma is the second most frequent malignant bone tumor. However, the etiological background of chondrosarcomagenesis remains largely unknown, along with details on molecular alterations and potential therapeutic targets. Massively parallel paired-end sequencing of whole genomes of 10 primary chondrosarcomas revealed that the process of accumulation of somatic mutations is homogeneous irrespective of the pathological subtype or the presence of IDH1 mutations, is unique among a range of cancer types, and shares significant commonalities with that of prostate cancer. Clusters of structural alterations localized within a single chromosome were observed in four cases. Combined with targeted resequencing of additional cartilaginous tumor cohorts, we identified somatic alterations of the COL2Al gene, which encodes an essential extracellular matrix protein in chondroskeletal development, in $19.3 \%$ of chondrosarcoma and $31.7 \%$ of enchondroma cases. Epigenetic regulators (IDH1 and YEATS2) and an activin/BMP signal component (ACVR2A) were recurrently altered. Furthermore, a novel FN1-ACVR2A fusion transcript was observed in both chondrosarcoma and osteochondromatosis cases. With the characteristic accumulative process of somatic changes as a background, molecular defects in chondrogenesis and aberrant epigenetic control are primarily causative of both benign and malignant cartilaginous tumors.
\end{abstract}

[Supplemental material is available for this article.]

Chondrosarcoma accounts for $>20 \%$ of primary bone sarcomas with an overall incidence rate estimated at approximately one in 200,000 (Whelan et al. 2012). The patients are mostly older than $50 \mathrm{yr}$ and show male dominance. There are two common subtypes: central and peripheral. Central chondrosarcoma predominates $(\sim 80 \%)$ and arises in the medullary cavity of the long bone, while peripheral chondrosarcoma $(\sim 15 \%)$ develops from the surface of the bone (Fletcher et al. 2002; Bovée et al. 2010). Clinically, low-grade chondrosarcomas rarely metastasize and can be managed with local resection. In contrast, high-grade chondrosarcomas often metastasize and are lethal in most cases. Since the tumor cells exist in specific microenvironments such as low vascularity and accumulated extracellular matrix, they are largely resistant to conventional chemotherapy and radiotherapy. Therefore, identification of new therapeutic targets is required for this tumor.

Benign cartilage tumors (enchondroma and osteochondroma) may progress to chondrosarcoma (Bovée et al. 2010). Mutations of exostosin 1 (EXT1) and EXT2 genes are linked to hereditary and sporadic osteochondromatosis and are also reported in chondrosarcoma (Hecht et al. 1997; Wuyts et al. 1998). EXT1 and EXT2 regulate proper heparan sulfate proteoglycan processing, and their defects cause abnormal diffusion of hedgehog ligands (Koziel et al.

\section{Corresponding author: tashibat@ncc.go.jp}

Article published online before print. Article, supplemental material, and publication date are at http://www.genome.org/cgi/doi/10.1101/gr.160598.113.
2004). Mutations in the PTH1R gene were also identified in enchondroma, which disrupts the IHH-PTHLH feedback loop and also induces constitutive hedgehog signaling (Hopyan et al. 2002). Consistently transgenic mice that express Gli2-a downstream effector of the hedgehog signal-in chondrocytes develop cartilaginous lesions similar to human enchondromas (Hopyan et al. 2002).

In addition to hedgehog signaling, alterations of other molecular pathways such as TP53/MDM2 (Wadayama et al. 1993; Larramendy et al. 1997), AKT1 (Schrage et al. 2009), and CDK4/RB (Asp et al. 2001) have been reported in chondrosarcomas. Recently, frequent somatic mutations in isocitrate dehydrogenase 1 (IDH1) and IDH2 have been identified in both enchondroma and central chondrosarcoma (Amary et al. 2011a), and somatic mosaic IDH1/2 mutations are associated with multiple enchondromatosis (Amary et al. 2011b; Pansuriya et al. 2011). These molecular and genetic observations support a close association between benign osteocartilaginous tumors and chondrosarcoma; however, the detailed molecular events and etiological risk factors underlying chondrosarcomagenesis remain largely unknown.

(C) 2014 Totoki et al. This article is distributed exclusively by Cold Spring Harbor Laboratory Press for the first six months after the full-issue publication date (see http://genome.cshlp.org/site/misc/terms.xhtml). After six months, it is available under a Creative Commons License (Attribution-NonCommercial 4.0 International), as described at http://creativecommons.org/licenses/by-nc/ $4.0 \%$ 


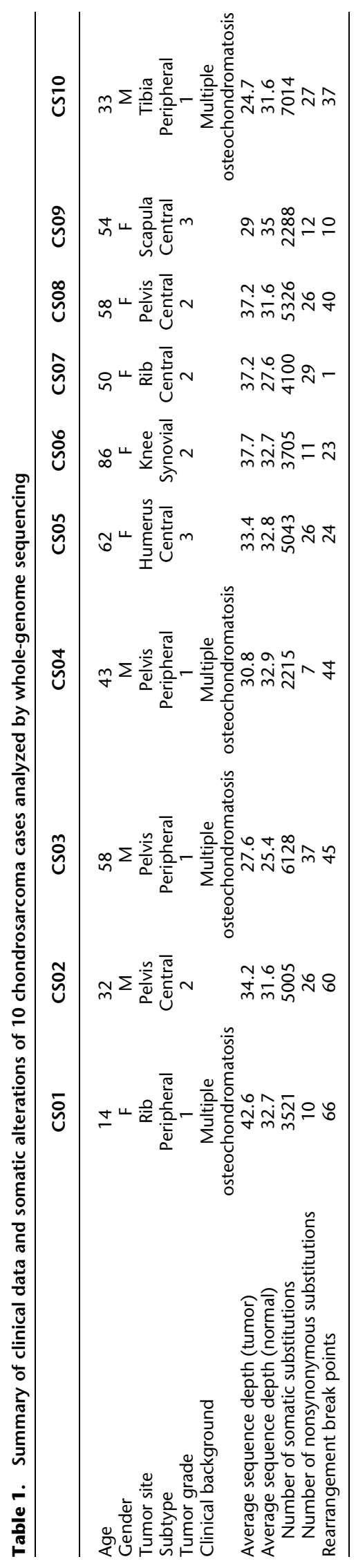




\section{Results}

\section{Whole-genome sequencing (WGS) of chondrosarcoma}

Massively parallel paired-end sequencing of the whole genomes of 10 pairs of primary chondrosarcoma and matched normal muscle tissues was performed. The cases included five central, four peripheral, and one synovial-a rare subtype (Table 1 ). The median sequence coverage was $33.4 \times$ for tumor tissue and $31.4 \times$ for normal tissue (Table 1). All peripheral cases were associated with osteochondromatosis and harbored germline EXT1 or EXT2 mutations (Supplemental Table S1). No IDH1/2 or other enchondromatosis-associated gene mutations (PTH1R, PTPN11, or ACP5) (Hopyan et al. 2002; Bowen et al. 2011; Briggs et al. 2011) were observed in the germline genomes. In total, 44,345 somatic singlenucleotide variations (SNVs; ranging from 2215-7014 per genome, $1.55 / \mathrm{Mb}$ on average) and 4096 small insertions/deletions (indels, ranging from 269-544 per genome) were identified (Fig. 1A; Supplemental Table S2). The somatic point mutations included 211 nonsynonymous mutations (21.1 per genome on average) and 14 indels (1.4 per genome on average) in the coding regions (Sup- plemental Table S3). More than 91\% (78/85) of somatic substitutions and $63 \%(17 / 27)$ of somatic indels were validated by Sanger sequencing. These mutations were significantly enriched in membranous proteins, especially those with transmembrane receptor activity (Supplemental Table S4).

\section{Unique somatic substitution signatures in the chondrosarcoma genomes}

Analysis of genome-wide somatic mutation signatures revealed that $\mathrm{C}: \mathrm{G}>\mathrm{T}: \mathrm{A}$ transitions are dominant, followed by $\mathrm{T}: \mathrm{A}>\mathrm{C}: \mathrm{G}, \mathrm{T}: \mathrm{A}>\mathrm{A}: \mathrm{T}$, and $C: G>A: T$ substitutions in all chondrosarcoma cases (Fig. 1A). These somatic substitution signatures at $\mathrm{CpG}$ sites were not associated with subtype classification or the presence of $I D H 1$ mutations (Supplemental Figs. S1, S2). Principal component analysis of transcancer genome data showed that the substitution pattern in these chondrosarcomas was most similar to those of prostate (Berger et al. 2011) and liver (Fujimoto et al. 2012) cancers and chronic lymphocytic leukemia (permutation test; $P=0.0010$ ) (Fig. 1B; Puente et al. 2011). A significant reduction in $C: G>A: T$ transversions on the
A

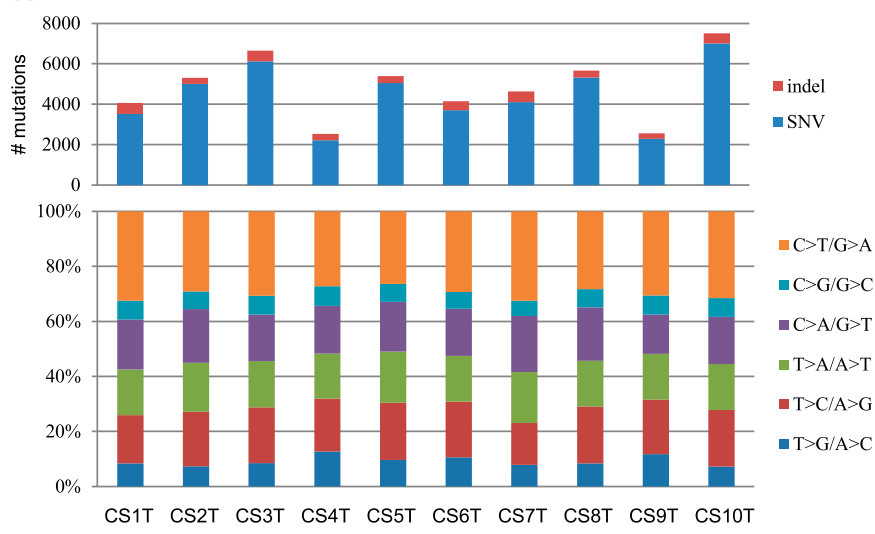

C
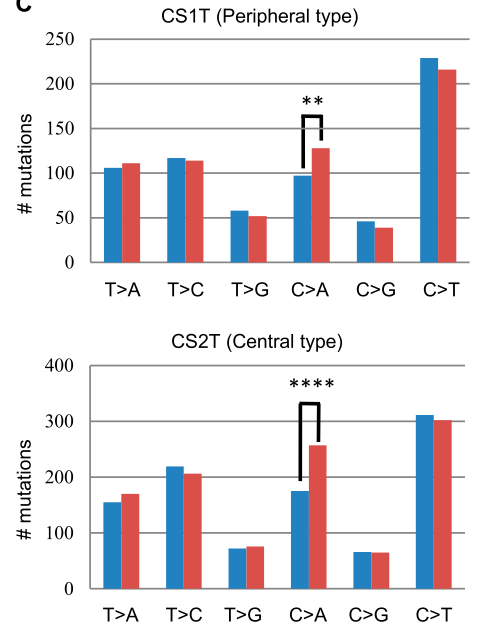

D

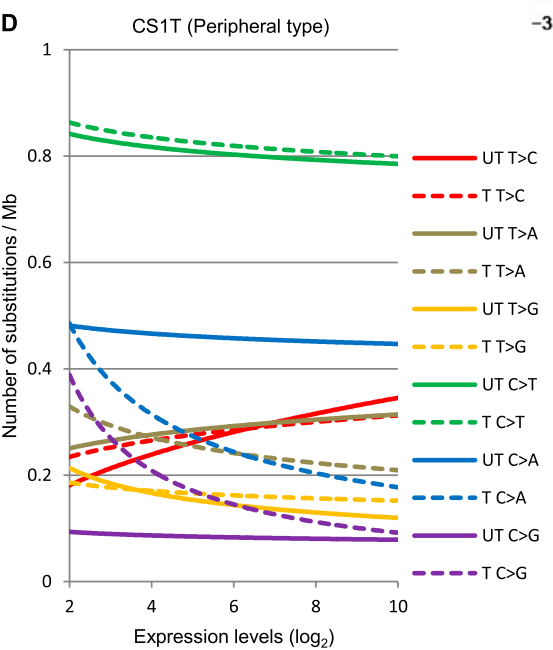

B

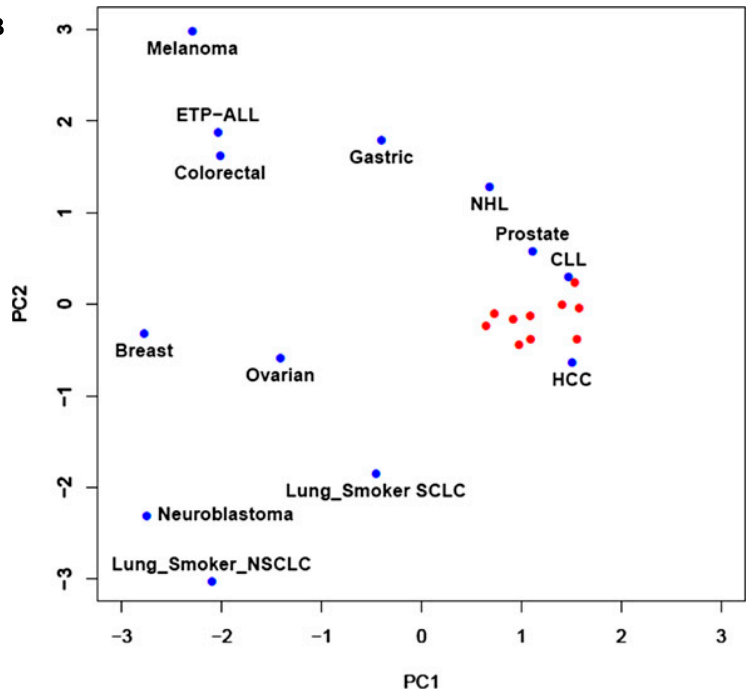

Figure 1. Somatic mutation signature of chondrosarcoma. (A, upper panel) Number of somatic substitutions and indels in 10 chondrosarcoma cases. (Lower panel) Percentage of six somatic substitutions in each case. (B) Principal component analysis of six substitution patterns in various cancer genomes including chondrosarcoma. Red dots indicate each chondrosarcoma case from the present study. (C) Number of somatic substitutions on transcribed (blue) and untranscribed (red) strands. A significant reduction of $\mathrm{C}>\mathrm{A}$ substitution was noted on the transcribed strand. $\left(^{* *}\right) P<0.01 ;\left({ }^{* * * *}\right) P<0.0001 .(D)$ Negative correlation between number of $C>A$ substitutions on the transcribed strand and gene expression level. (Blue) $C>A$ substitution; (solid line) untranscribed strand; (dotted line) transcribed strand. 
transcribed strand was observed in both central (CS-2T, 7T, 8T, and 9T) and peripheral (CS-1T, 3T, and 10T) cases (Fig. 1C; Supplemental Fig. S3), which correlated with gene expression level (Fig. 1D). To explore any sequence context-dependent substitutions in the chondrosarcoma genomes, we measured the frequencies of immediate $5^{\prime}$ and $3^{\prime}$ nucleotides for all substitutions. This analysis revealed significant increases in $\mathrm{C}>\mathrm{T}$ transitions at $\mathrm{TpCpT}, \mathrm{C}>\mathrm{A}$ transversions at $\mathrm{ApCpA}$, and $\mathrm{T}>\mathrm{A}$ transversions at $\mathrm{ApTpA}$ in all cases except CS5T (Fig. 2A; Supplemental Fig. S4). No context-specific $\mathrm{T}>\mathrm{C}$ transitions were observed. This triplet landscape differs from those of liver cancer and CLL and those caused by known etiological factors such as $\mathrm{C}>\mathrm{T}$ in UV-associated melanoma (Pleasance et al. 2010a) or $\mathrm{C}>\mathrm{A}$ in smoking-associated lung cancer (Pleasance et al. $2010 \mathrm{~b}$ ), but shares significant commonalities with that of prostate cancer (permutation test; $P=0.0017$ ) (Fig. 2B; Supplemental Figs. S5, S6). A further context survey of the 10 nucleotides stretching in the $5^{\prime}$ and $3^{\prime}$ directions from each somatic substitution identified a predominance of $\mathrm{A} / \mathrm{T}$ around the sites of the $\mathrm{C}>\mathrm{A}$ substitutions (particularly on the 3 ' side), and found that $\mathrm{T}$ was dominant at either side of the $\mathrm{C}>\mathrm{T}$ substitution (Fig. 3). This pattern was also observed in prostate cancer but not in melanoma and smoking-associated lung cancer (Fig. 3; Supplemental Fig. S7).

\section{Structural alterations in chondrosarcoma}

We determined copy number and structural alterations by analyzing sequence depth and paired sequence reads (Supplemental Tables S5, S6). We predicted 350 rearrangements in 10 chondrosarcomas. Validation analysis by genomic PCR and Sanger sequencing of randomly selected breakpoints verified $>98 \%$ of predictions $(67 / 68)$ as somatic. No recurrent rearrangements were detected. A remark- ably complex rearrangement-a cluster of structural alterations localized within a single chromosome-was observed in four cases (Supplemental Figs. S8, S9A-C). Massive rearrangements were involved in CS2T with amplification in the short arm of chromosome 5 , including the TERT gene (Figs. 4A,B). Interstitial deletion of exons 2 and 3 and a resulting premature stop codon in the WNK2 tumor suppressor gene (Hong et al. 2007), which encodes a negative regulator of the MEK/ERK pathway (Moniz et al. 2007), was detected in CS6T (Fig. 4C).

\section{Novel driver genes in chondrosarcoma}

To explore driving alterations in chondrosarcomagenesis, we calculated the expected number of somatic nonsynonymous and splice site substitutions, coding indels, and rearrangements with an adjustment for background mutation rate and gene length in each gene, and we identified five recurrently altered genes (IDH1, TP53, ACVR2A, COL2A1, and YEATS2) with a false-discovery rate of $<1 \%$ (Supplemental Table S7). Among these, recurrent mutations of the IDH1 and TP53 genes have been previously reported in chondrosarcoma (Wadayama et al. 1993; Amary et al. 2011a). To validate mutation frequency in a larger number of cases, we performed target exon resequencing of three potential new driver genes (COL2A1, YEATS2, and ACVR2A) and IDH1/2 in an additional 47 chondrosarcoma, with 19 corresponding adjacent nontumor tissues, and in 41 enchondroma samples (Fig. 5; Supplemental Tables S8, S9). COL $2 A 1$ encodes the alpha 1 chain of type II collagen which is enriched in cartilage (Cheah et al. 1985) and was mutated in 11 chondrosarcoma (19.3\%) and 13 enchondroma cases (31.7\%). Structural alterations (intragenic tandem duplication and deletion) of the COL2A1 gene were also detected. YEATS2 alterations, in-

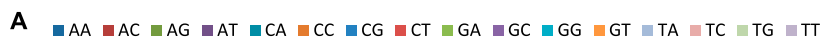
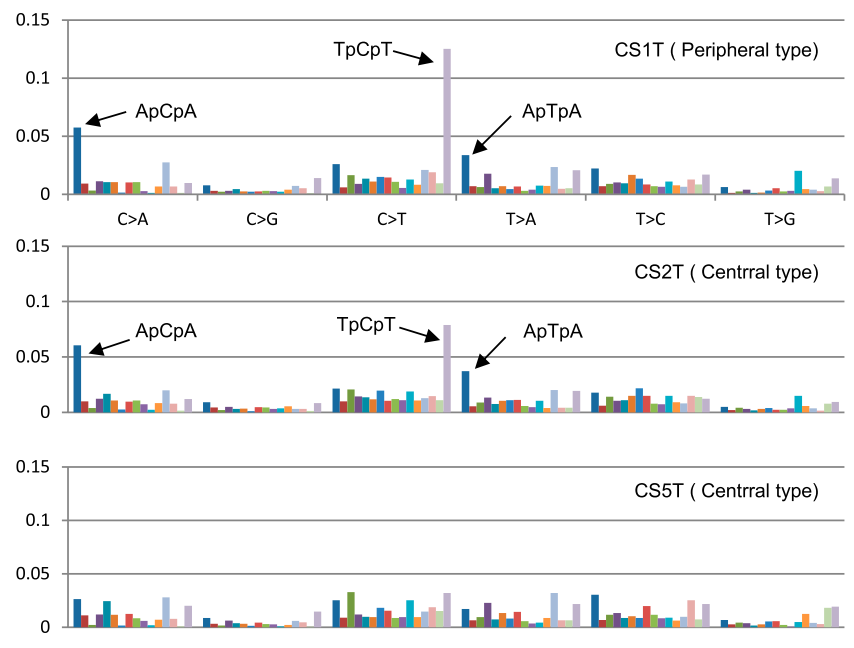

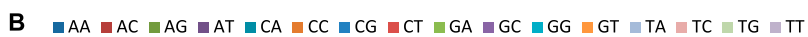
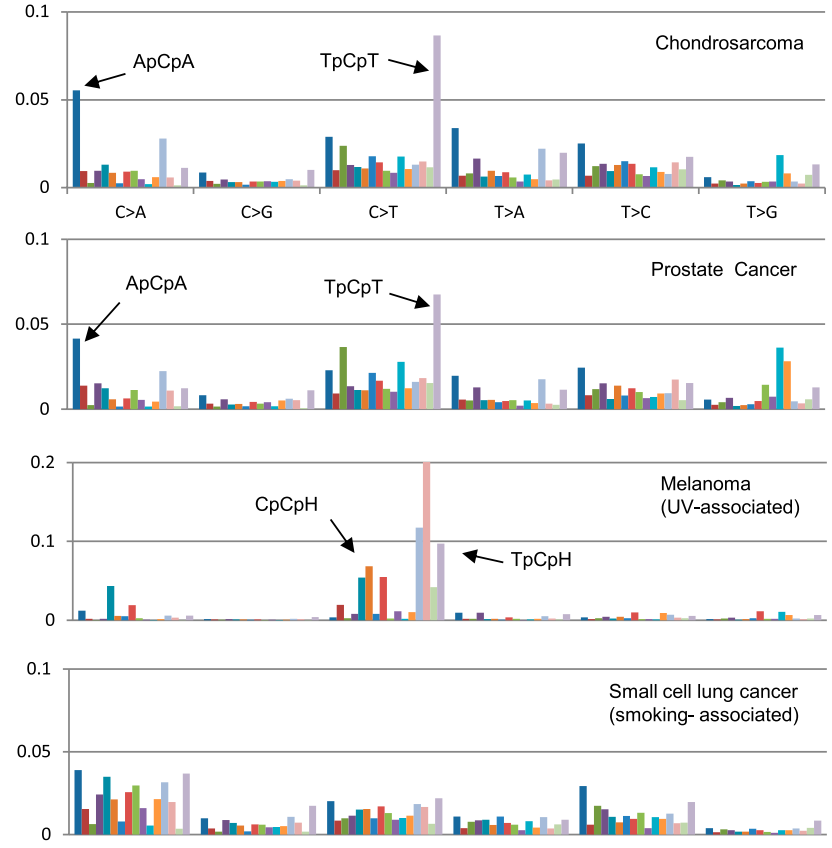

Figure 2. Somatic mutation portraits in the chondrosarcoma genome. $(A)$ Frequencies of 96 mutation portraits (combination of immediate $5^{\prime}$ and $3^{\prime}$ bases with six substitutions) in peripheral (CS1T) and central (CS2T and CS5T) cases. Sixteen triplet sequence patterns (mutations with immediate $5^{\prime}$ and $3^{\prime}$ nucleotides) for each substitution are indicated by different color columns. (B) Frequencies of 96 mutation portraits in chondrosarcoma (average), prostate cancer (average), UV-associated melanoma, and smoking-associated lung cancer genomes.

\section{Genome Research} www.genome.org 
A
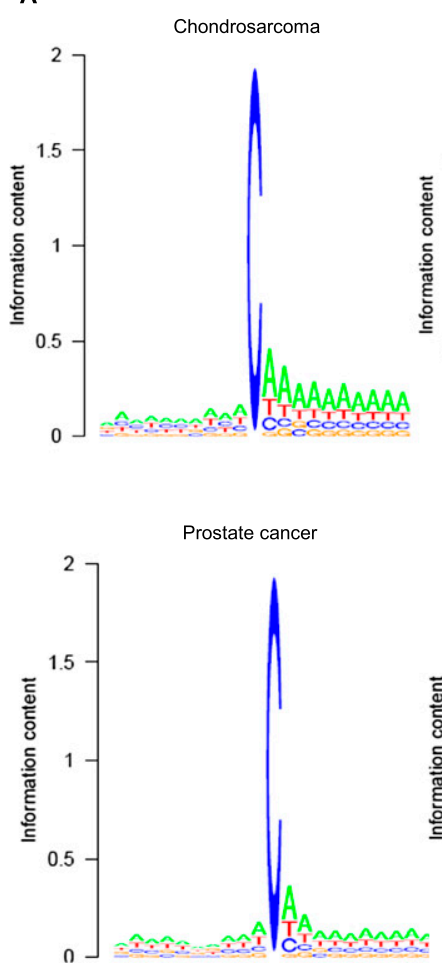

$\mathrm{C}>\mathrm{A}$

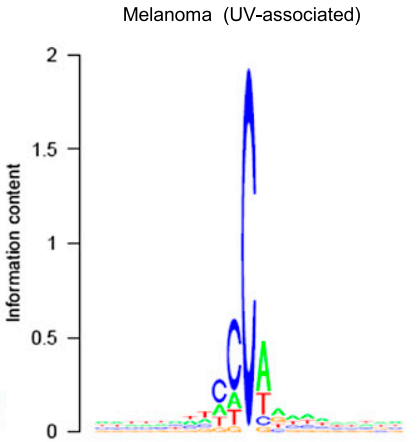

Small cell lung cancer

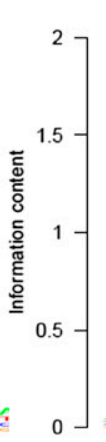

B

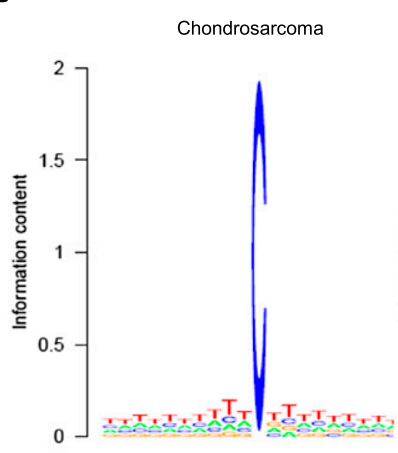

$C>T$
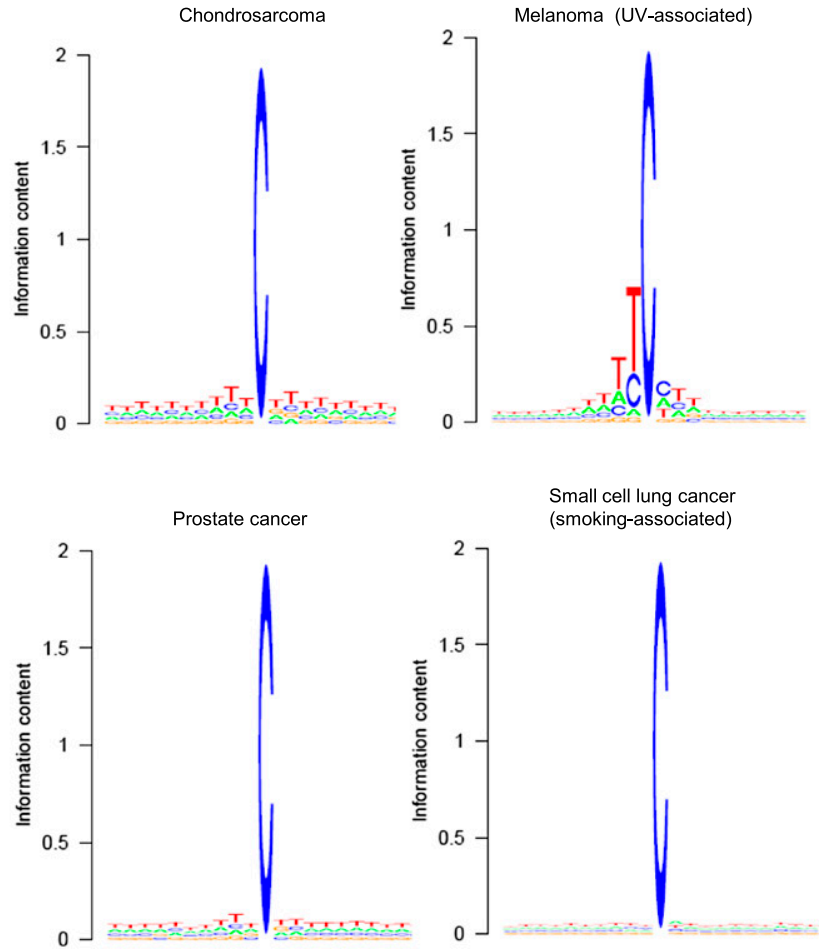

Figure 3. Characteristic base contexts at $C>A$ and $C>T$ mutations in chondrosarcoma. Sequence logos of consensus surrounding sequences enriched at $\mathrm{C}>\mathrm{A}(A)$ and $\mathrm{C}>\mathrm{T}(B)$ mutations in chondrosarcoma (top left), prostate cancer (bottom left), melanoma (top right), and smoking-associated, small-cell lung cancer (bottom right). The $x$-axis indicates base position with respect to the mutation site (center, mutation; left, 5' from the mutation; right, 3' from the mutation). The $y$-axis indicates the information content at each position in the sequence.

cluding one nonsense mutation and an intrachromosomal inversion, were detected in seven chondrosarcoma (12.3\%) cases and one enchondroma case (2.4\%). YEATS2 is a scaffolding subunit of the nuclear acetyltransferase complex which targets histone $\mathrm{H} 3$ and represses transcription of target genes (Wang et al. 2008), and a nonsense mutation (p.W1229*) that disrupts the regulatory histone fold module (Fig. 5B). They are significantly more frequent in higher-grade (grades 2 and 3 ) cases than grade 1 chondrosarcoma/ enchondroma cases $(P=0.023)$ and tend to be mutually exclusive to COL2A1 mutation $(P=0.07)$. ACVR2A mutations were observed in four chondrosarcoma cases $(7 \%)$ and three enchondroma cases (7.3\%). IDH1 mutations at codon 132 were observed in 12 chondrosarcoma (21.1\%) and five enchondroma cases (12.2\%) and were not associated with any other mutations. The presence of a COL2A1 or IDH1 mutation was not associated with patients' prognoses (Supplemental Fig. S10).

\section{Novel fusion gene in chondrosarcoma}

Four in-frame fusion transcripts were predicted by structural rearrangements (Table 2). Among these, two (ACVR2A-FN1 and FN1$A C V R 2 A)$ were expressed and validated in the synovial CS6T case (Fig. 6A-C; Supplemental Fig. S11). Paired-end whole-transcriptome sequencing demonstrated that expression of the ACVR2A gene transcript increased sharply-more than 10-fold-in the exons fused to the FN1 gene (Fig. 6D), without any overt change in FN1 gene expression at the fusion junction (Supplemental Fig. S12). This suggests that promoter activity of the FN1 gene conferred increased FN1-ACVR2A transcript in the tumor. RNA sequencing further revealed that expression of the $A C V R 2 A$ gene increased more than 25-fold in the FN1-ACVR2A fusion-positive case (CS6T) compared with that of other samples (CS1T and CS7T) (Supplemental Table S10). Since this fusion gene was detected in a chondrosarcoma with features suggestive of preexisting synovial osteochondromatosis (Fig. 6A), we further surveyed a range of cartilaginous tumors, including extramedullary ones (17 chondrosarcomas, seven synovial chondromatoses, and 13 osteochondromas) using RT-PCR, and detected expression of the FN1-ACVR2A-but not the ACVR2AFN1-fusion transcript in a case of osteochondromatosis (Fig. 6E; Supplemental Fig. S13).

\section{Discussion}

Using the whole-genome sequencing (WGS) approach, the present study revealed comprehensive landscapes of genetic alterations in the chondrosarcoma genome that include global mutational signatures, structural alterations including copy number changes and rearrangements, and new driver genes.

Somatic mutation signatures are affected by both environmental carcinogen exposures and defects in DNA repair systems (Stratton et al. 2009; Nik-Zainal et al. 2012). Previous WGS analyses of small-cell lung cancer and melanoma cell lines showed an intimate association between specific carcinogens (smoking or UV exposure) and the patterns of base substitutions (Pleasance et al. $2010 a, b)$. Furthermore, WGS of breast cancers have reported that BRCA1-mutated breast cancers showed a unique mutational signature (Nik-Zainal et al. 2012). Our analysis showed that C:G>T:A transitions with significant transcription-coupled repair are broadly observed in chondrosarcoma, which is also characteristic of smokingassociated lung cancer (Pleasance et al. 2010b; Govindan et al. 2012). 
A

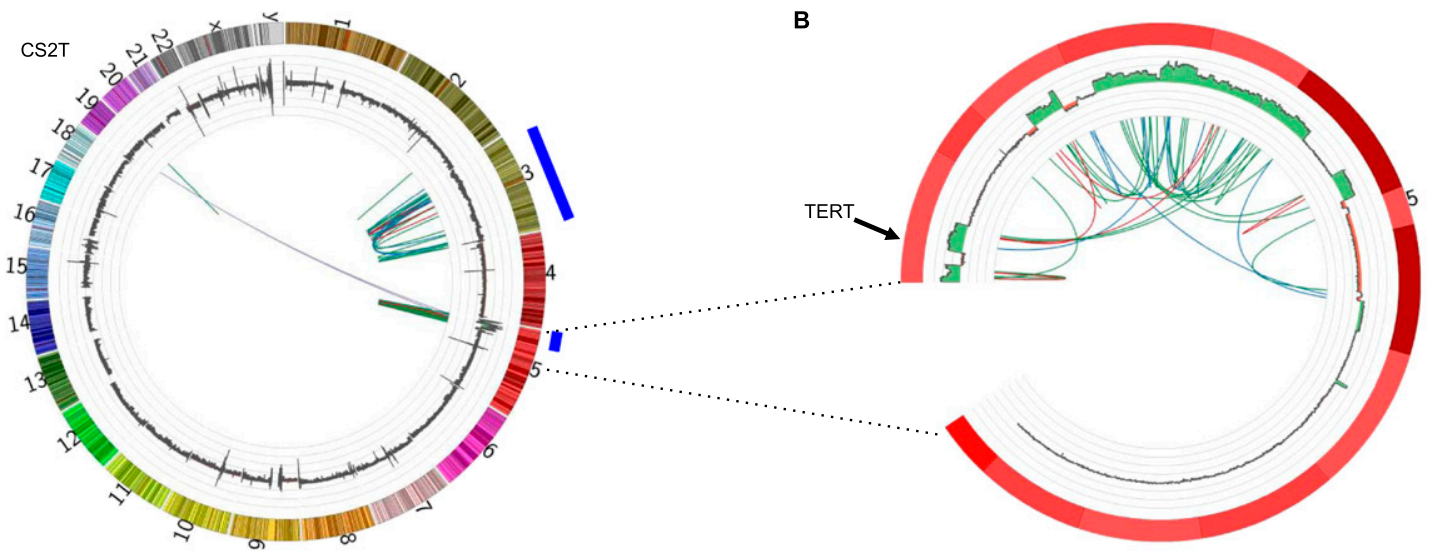

c
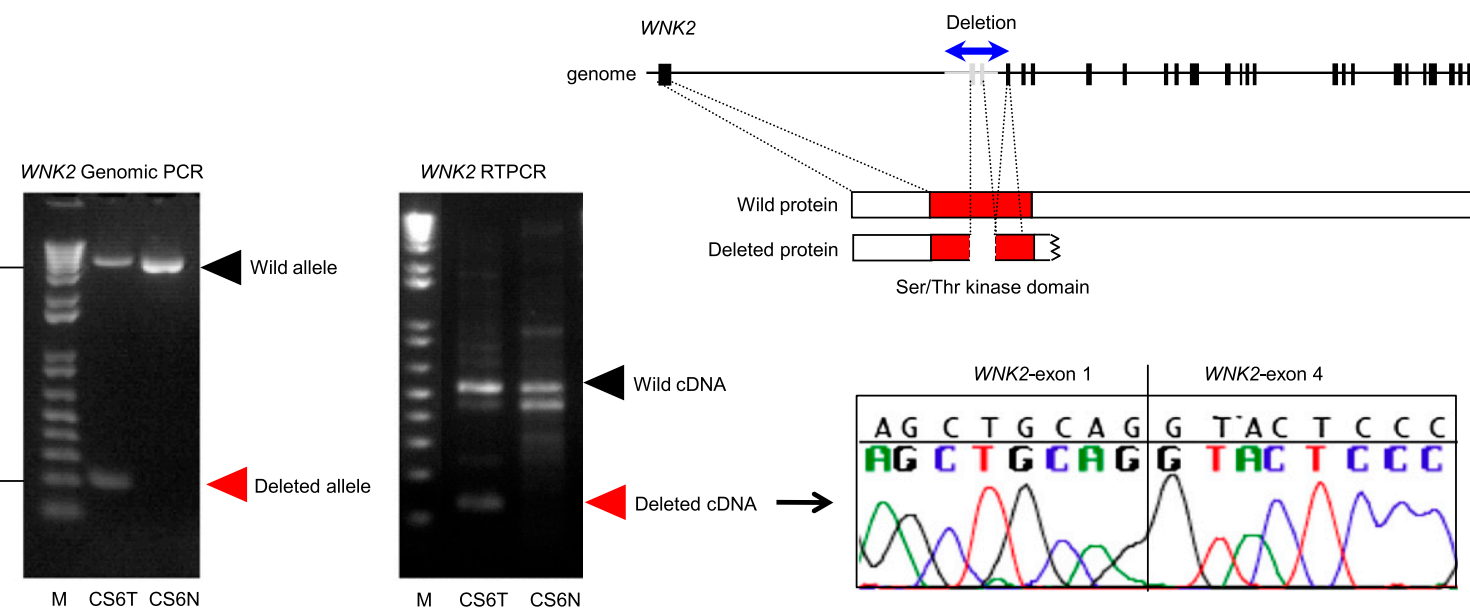

Figure 4. Structural alterations in chondrosarcoma. (A) Complex rearrangements in CS2T indicated by a Circos plot (Krzywinski et al. 2009). Structural alterations (red line, deletion; green line, inversion; blue line, tandem duplication; purple line, translocation) are shown in the inner circle. Copy number changes (green, copy gain/amplification; red, copy loss) are shown in the outer circle. Thick blue lines indicate regions of localized accumulation of structural alterations. (B) Massive structural alterations in the short arm of chromosome 5 in CS2T. The location of the TERT gene is indicated by an arrow. (C) Interstitial deletion in the WNK2 gene in CS6T. (Top) Schematic representation of exon 2-3 deletion in the WNK2 gene and its protein product. (Bottom left) Validation of the predicted deletion by genomic PCR and RT-PCR. (Bottom right) Sanger sequencing validation of the exon 2-3 deleted transcript.

Nonetheless, further mutation trait analysis demonstrated that the mutagenesis process in chondrosarcoma seems to be distinct from mutagenesis induced by known carcinogens, including tobacco smoking. The presence of an IDH1 mutation is associated with epigenetic alterations such as CpG hypermethylation in tumors, including enchondroma (Pansuriya et al. 2011; Turcan et al. 2012). It could be possible that frequent $\mathrm{CpG}$ methylation induces the chance of somatic C-to-T transition by spontaneous deamination of 5-methylcytosine. However, the genome sequencing described here revealed that the IDH1 mutation exerts no significant effect on the somatic mutation frequency at CpG sites during chondrosarcomagenesis.

Our analysis uncovered the unexpected similarity of the mutation portraits $(\mathrm{C}>\mathrm{T}$ transitions at $\mathrm{TpCpT}, \mathrm{C}>\mathrm{A}$ transversions at ApCpA, and $\mathrm{T}>\mathrm{A}$ transversions at ApTpA) of chondrosarcoma and prostate cancer, both of which frequently occur in older and male patients. Nine out of 10 cases showed similar mutational signatures, and these nine cases harbored a distinct set of somatic mutations, suggesting that this signature could be caused by common etiological factors but not affected by somatic deficiency in the DNA repair system. The etiological risk factors, including genetic sus- ceptibility for chondrosarcoma, remain unknown partly because of the small number of patients; however, our observation implies that aging, hormonal status, or dietary factors, all of which are suggestive etiological factors of prostate cancer (Hsing and Chokkalingam 2006), or genetic risk factors, may be associated with this sarcoma.

WGS of 10 cases followed by further validation of a larger cohort identified a few common alterations (COL2A1 and IDH1) and other rarer events, the latter of which include progression-associated changes such as YEATS2, in chondrosarcomagenesis. COL2A1, which is rarely mutated in other tumor types, particularly emerged as a new frequently altered gene in chondrosarcoma. The pattern of COL2A1 mutation in this study is different from that reported in the previous study (Tarpey et al. 2013). A preponderance of missense mutation has been observed in the present study whereas truncating mutations were predominant in the previous report. This discrepancy could be due to the difference in ethnicity (Japanese and Caucasian) or unknown carcinogenesis background of each cohort, and a larger collection of samples by an international collaboration will be required to explore this. Germline COL2A1 mutations are associated with a number of chondroskeletal malformation syndromes, so-called type II collagenopathies (Spranger et al. 1994; 
A

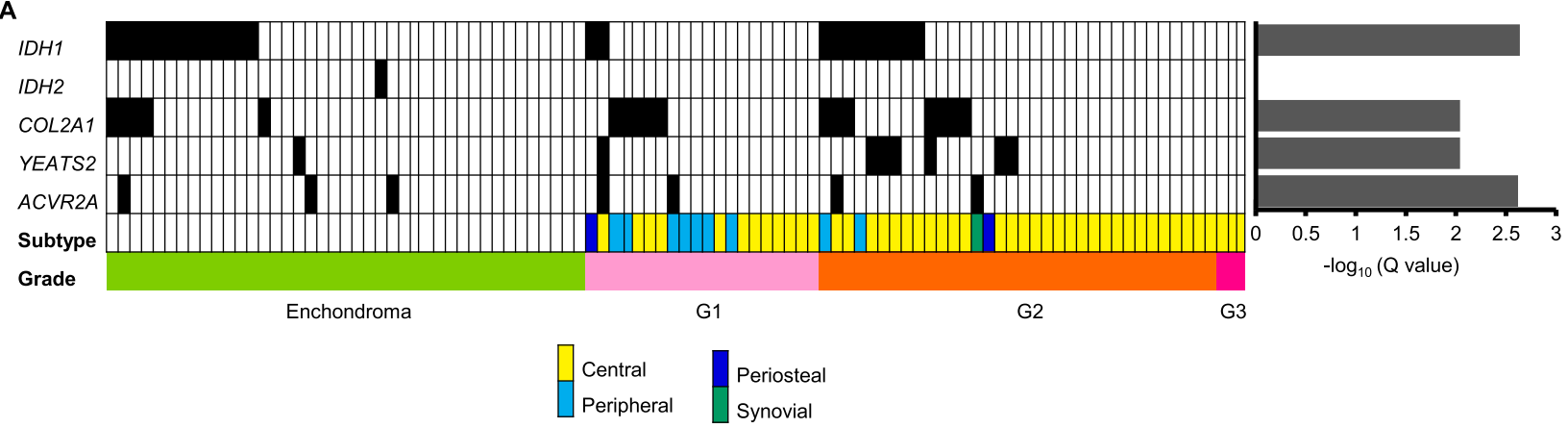

B COL2A1

Chondrosarcoma

Enchondroma
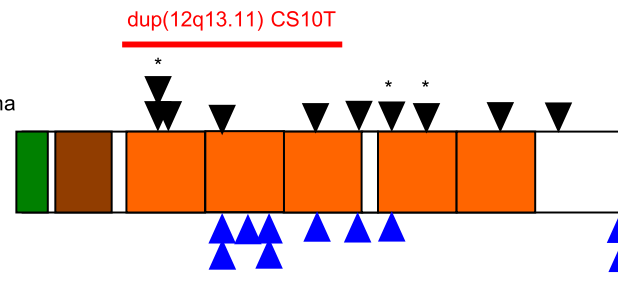

YEATS2

Chondrosarcoma

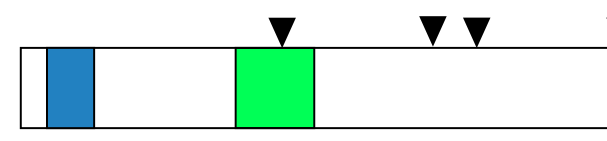

Enchondroma
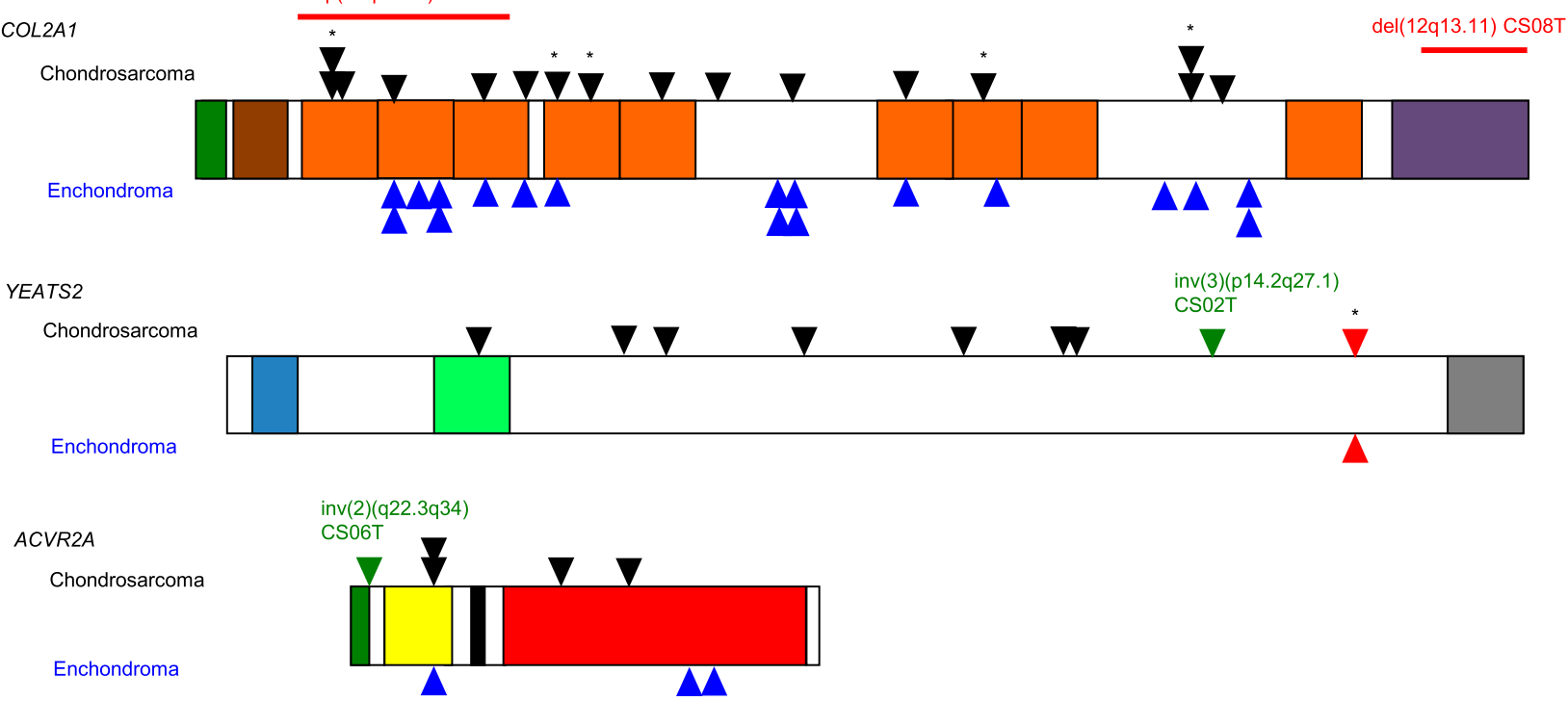

Figure 5. Mutation landscape of chondrosarcoma. $(A)$ Enchondroma and chondrosarcoma samples were displayed with the presence of the $I D H 1 / 2$, COL2A1, YEATS2, and ACVR2A genes; tumor subtype; and grade (G1-G3). The Q-value for mutated genes is shown on the right. (B) Distribution of mutations and rearrangements in the coding regions of COL2A1, YEATS2, and ACVR2A genes. Black and blue arrowheads indicate missense mutations in chondrosarcoma and enchondroma, respectively. Red and green arrowheads indicate non-sense mutation and the position of intrachromosomal inversion. Asterisks indicate mutations verified as somatically acquired by sequencing the corresponding normal genome. Colored boxes indicate functional domains in each molecule (green, signal peptide; brown, von Willebrand factor type $C$ domain; orange, collagen triple helix repeat; purple, fibrillar collagen C-terminal domain; blue, coiled-coil domain; light green, YEATS family domain; gray, histone fold domain; yellow, activin types I and II receptor domain; black, transmembrane domain; red, serine/threonine protein kinase domain).

Nishimura et al. 2005), including spondyloepiphyseal dysplasia congenita, achondrogenesis type II, and osteoarthritis associated with chondrodysplasia. Col2a1 mutant mice demonstrated growth plate disorganization with reduced elaborate collagen fibrils (Esapa et al. 2012). However, no clinical association between these congenital diseases and cartilaginous tumors has been reported so far. The presence of frequent COL $2 A 1$ as well as IDH1/2 mutations in both chondrosarcoma and enchondroma demonstrated by the present and previous studies (Amary et al. 2011a) supports a model of progression from enchondroma to chondrosarcoma. Our analysis also identified that aberrations in the epigenetic regulators play important roles in cartilaginous tumors. The presence of an IDH1 mutation is associated with CpG hypermethylation in tumors including enchondroma (Pansuriya et al. 2011; Turcan et al. 2012). YEATS2 is a scaffolding subunit of the nuclear acetyltransferase complex and harbors a histone-like module that interacts with TATA-binding protein and negatively regulates gene transcription (Wang et al. 2008). Somatic mutations in the YEATS2 gene have also been reported in lung $(3.8 \%)$, colorectal $(1.8 \%)$, and endometrial (1.8\%) cancers in the COSMIC database (Forbes et al. 2011).

No disease-specific common fusion gene was detected in our cohort of chondrosarcomas. However, analysis of a synovial subtype

Table 2. Inframe fusion genes detected in chondrosarcoma

\begin{tabular}{lcccrrr}
\hline Fusion gene & Sample & Rearrangement type & Chromosome 1 & Position 1 & Chromosome 2 & Position 2 \\
\hline PDE1C-MACC1 & CS01T & Deletion & chr7 & $20,201,367$ & chr7 & $32,263,702$ \\
LIPI-FAM176C & CS03T & Inversion & chr21 & $15,528,857$ & chr21 & $33,858,432$ \\
ACVR2A-FN1 & CS06T & Inversion & chr2 & $148,646,674$ & chr2 & $216,289,052$ \\
FN1-ACVR2A & CS06T & Inversion & chr2 & $148,646,754$ & chr2 & $216,289,134$ \\
\hline
\end{tabular}


A

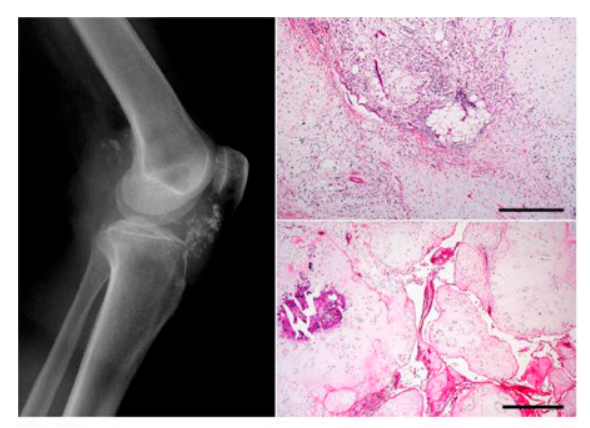

B
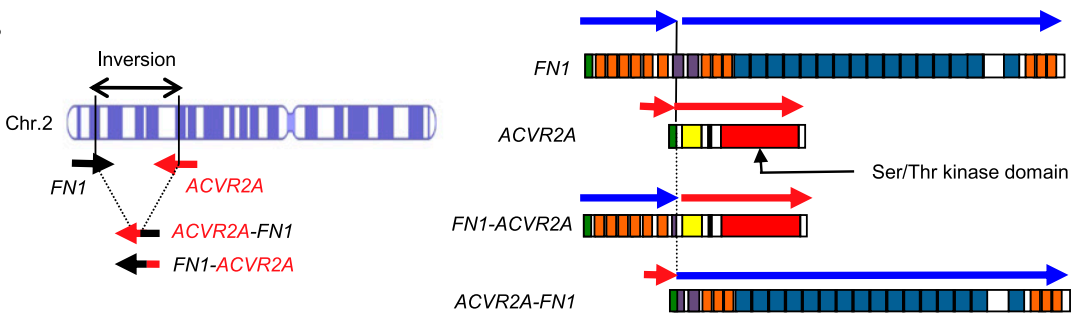

C

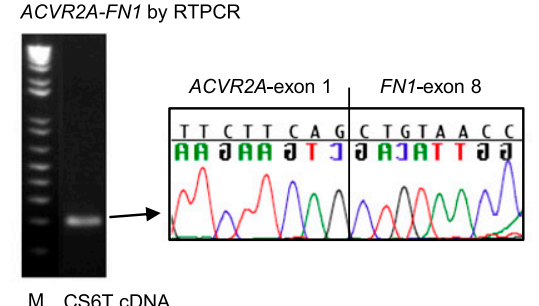

FN1-ACVR2A by RTPCR

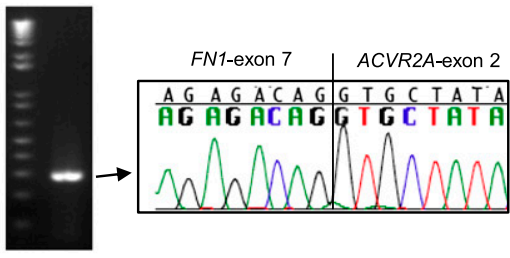

M CS6T cDNA
D

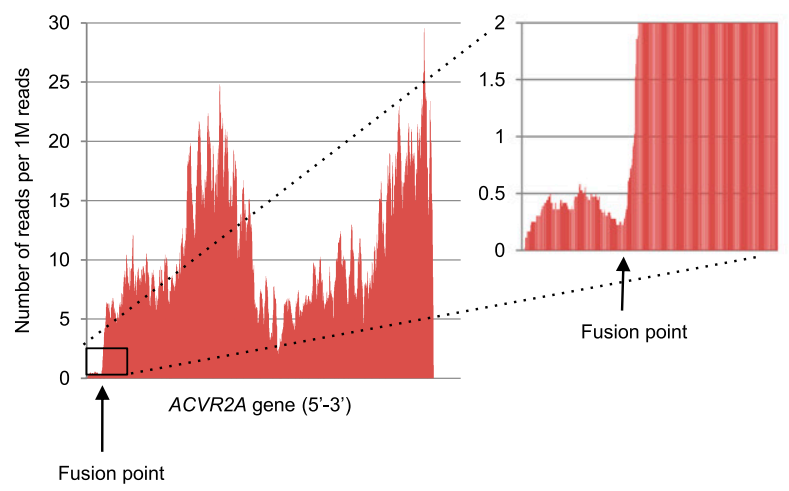

E

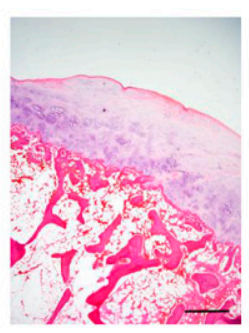

FN1-ACVR2A by RTPCR
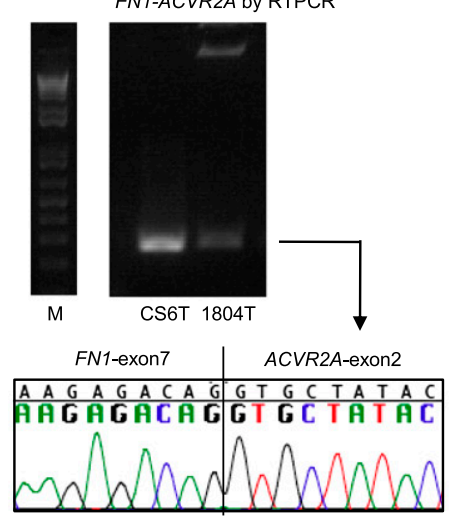

Figure 6. FN1-ACVR2A fusion gene in chondrosarcoma. (A) Synovial chondrosarcoma case. (Left panel) Radiograph revealed a calcified soft tissue mass surrounding the knee joint without bone involvement. (Right, lower panel) This hypercellular myxoid tumor diffusely infiltrated periarticular and subcutaneous tissues, dissecting through fat and collagen (scale bar, $500 \mu \mathrm{m}$ ). (Right, upper panel) The tumor focally resembled synovial chondromatosis (scale bar, $1 \mathrm{~mm}$ ) and later metastasized to the inguinal lymph node. (B) Schematic presentation of an intrachromosomal inversion in chromosome 2q (left) and two in-frame fusion proteins generated by this rearrangement. (C) Validation of fusion transcripts (left, ACVR2A-FN1, and right, FN1-ACVR2A) by RT-PCR and Sanger sequencing. (D) Estimation of $A C V R 2 A$ gene expression at nucleotide resolution by counting RNA sequencing reads. Note the sharp increase in AVCR2A expression after the fusion point. ( $E$, left) Histology of the multiple osteochondroma case. This tibial tumor is composed of exophytic bony growth capped by benign hyaline cartilage (scale bar, $1 \mathrm{~mm}$ ). (Right) Validation of the FN1-ACVR2A fusion transcript by RT-PCR and Sanger sequencing in an osteochondromatosis case (1804T).

identified recurrent FN1-ACVR2A fusion transcript, which further suggests a molecular link between chondrosarcoma and osteochondromatosis. $A C V R 2 A$ encodes a membranous serine/threonine protein kinase which functions as a receptor for the activin and bone morphogenetic proteins 4 and 6 (Donaldson et al. 1992) and is involved in skeletal development (Matzuk et al. 1995). The FN1-ALK fusion transcript has been identified as a potential therapeutic target in ovarian cancer (Ren et al. 2012).

Collectively, our analysis demonstrated that molecular defects in chondrocyte differentiation and epigenetic regulators are synergistically causative of both benign and malignant cartilaginous tumors (Supplemental Fig. S14). A recent study reported the potential efficacy of an IDH1 inhibitor for treating IDH1-mutated tumors (Rohle et al. 2013). Aberrant FN1-ACVR2A gene fusion and recurrent $A C V R 2 A$ mutations also warrant small-molecular inhibitors targeting activin receptor kinases (Harrison et al. 2005) as potential therapeutic modalities against a subset of chondrosarcoma.

\section{Methods}

\section{Clinical samples}

The clinical and pathological features of 10 patients and their tumors are shown in Supplemental Table S1. Tissue samples were provided by the National Cancer Center Biobank, Japan. Highmolecular-weight genomic DNA and RNA were extracted from fresh frozen tumor specimens and noncancerous muscle tissue. The study protocol was in agreement with the Ethical Committee of the National Cancer Center, Tokyo, Japan.

\section{Whole-genome and transcriptome sequencing}

We prepared 300- to 500-bp insert libraries from $3 \mu \mathrm{g}$ of genomic DNA and 150- to 200-bp insert libraries from $2 \mu \mathrm{g}$ of total RNA using the TruSeq DNA sample preparation kit and mRNA-Seq sample preparation kit (Illumina), respectively. The libraries were

\section{Genome Research} www.genome.org 
subjected to paired-end sequencing of $100 \mathrm{bp}$ on the HiSeq 2000 (Illumina) according to the manufacturer's instructions.

\section{Detection of somatic point mutations and short indels}

Paired-end reads were aligned to the human reference genome (GRCh37) using the Burrows-Wheeler aligner (BWA) (Li and Durbin 2009). Probable PCR duplications, in which paired-end reads aligned to the same genomic positions, were removed using SAMtools (Li et al. 2009) and a program developed in-house. To find somatic point mutations and short indels, SAMtools was applied with stringent confidence filtering conditions we developed (Totoki et al. 2011). The details of our filtering conditions are described in the Supplemental Information.

\section{Validation of candidate driver genes in an additional cohort}

To validate the mutation frequencies of COL2A1, YEATS2, and $A C V R 2 A$ with recurrent mutations in benign and malignant cartilaginous tumors, we amplified all protein-coding exons of those genes using formalin-fixed, paraffin-embedded (FFPE) DNA from 47 chondrosarcoma, 19 corresponding adjacent nontumor tissues, and 41 enchondroma samples. Six sequencing libraries were prepared from 115 amplicon mixtures of pooled DNA from three chondrosarcomas, pooled normal DNA, and pooled DNA from two enchondromas. The 115 amplicons covered a total of $20 \mathrm{~kb}$ of coding regions of the three genes. The six libraries were subjected to paired-end sequencing of $100 \mathrm{bp}$ using an Illumina GA IIx sequencer. Paired-end reads were aligned to the human reference genome (GRCh37) using BWA, and somatic mutations were called using SAMtools (Li et al. 2009) and programs developed in-house. All candidate 137 SNVs and 13 short indels for ACVR2A, COL2A1, and YEATS2 and the mutational hot spots for IDH1 and IDH2 were further verified in individual cases by the MassARRAY system (Sequenom). The primer sets, which include a pair of amplicon primers and an extension primer for each SNV, were designed using the MassARRAY Designer software (Sequenom) (Supplemental Table S11). The details of our filtering conditions of the mutation call and the verification by the MassARRAY system are described in the Supplemental Information.

\section{Fusion gene validation by RT-PCR and sequencing}

Total RNA was reverse-transcribed to cDNA using SuperScript III (Invitrogen). cDNA was subjected to PCR amplification using Ex Taq (Takara Bio). The PCR products were directly sequenced in both directions by Sanger sequencing using the BigDye Terminator kit (Applied Biosystems).

\section{Data access}

Sequence and mutation/indel data have been submitted to the European Genome-phenome Archive (EGA; https://www.ebi.ac. uk/ega/) under accession number EGAS00001000505.

\section{Acknowledgments}

We thank Dr. Toshifumi Ozaki, Department of Orthopaedic Surgery, Okayama University Medical School, for samples; Drs. S. Hosokawa and H. Iwama, Sequenom, for MassARRAY data analysis; and Ms. T. Urushidate, N. Okada, A. Kokubu, H. Shimizu, and $\mathrm{S}$. Ohashi for technical assistance. The supercomputing resource SHIROKANE was provided by the Human Genome Center at The University of Tokyo. This study was supported by the Program for Promotion of Fundamental Studies in Health Sciences from the
National Institute of Biomedical Innovation (NIBIO), National Cancer Center Research and Development Funds (23-A-8 and 23A-10), a Grant in Aid for Scientific Research B (22390296), and a Health Labor Sciences Research Grant. The National Cancer Center Biobank is supported by the National Cancer Center Research and Development Fund, Japan.

Author contributions: Conception and design by Y.T., A.Y., A.K., and T.S. Study materials and patients provided by A.Y., K.O., A.Y., T.F., and H.T. Data analysis and interpretations by Y.T., A.Y., F.H., H.N., N.H., Y.A., J.T., S.M., and T.S. Y.T., A.Y., A.K., and T.S. wrote the manuscript.

\section{References}

Amary MF, Bacsi K, Maggiani F, Damato S, Halai D, Berisha F, Pollock R, O'Donnell P, Grigoriadis A, Diss T, et al. 2011a. IDH1 and IDH2 mutations are frequent events in central chondrosarcoma and central and periosteal chondromas but not in other mesenchymal tumours. J Pathol 224: 334-343.

Amary MF, Damato S, Halai D, Eskandarpour M, Berisha F, Bonar F, McCarthy S, Fantin VR, Straley KS, Lobo S, et al. 2011b. Ollier disease and Maffucci syndrome are caused by somatic mosaic mutations of IDH1 and IDH2. Nat Genet 43: 1262-1265.

Asp J, Inerot S, Block JA, Lindahl A. 2001. Alterations in the regulatory pathway involving $\mathrm{p} 16, \mathrm{pRb}$ and cdk4 in human chondrosarcoma. J Orthop Res 19: 149-154.

Berger MF, Lawrence MS, Demichelis F, Drier Y, Cibulskis K, Sivachenko AY, Sboner A, Esgueva R, Pflueger D, Sougnez C, et al. 2011. The genomic complexity of primary human prostate cancer. Nature 470: 214-220.

Bovée JV, Hogendoorn PC, Wunder JS, Alman BA. 2010. Cartilage tumours and bone development: molecular pathology and possible therapeutic targets. Nat Rev Cancer 10: 481-488.

Bowen ME, Boyden ED, Holm IA, Campos-Xavier B, Bonafé L, SupertiFurga A, Ikegawa S, Cormier-Daire V, Bovée JV, Pansuriya TC, et al. 2011. Loss-of-function mutations in PTPN11 cause metachondromatosis, but not Ollier disease or Maffucci syndrome. PLoS Genet 7: e1002050.

Briggs TA, Rice GI, Daly S, Urquhart J, Gornall H, Bader-Meunier B, Baskar K, Baskar S, Baudouin V, Beresford MW, et al. 2011. Tartrate-resistant acid phosphatase deficiency causes a bone dysplasia with autoimmunity and a type I interferon expression signature. Nat Genet 43: 127-131.

Cheah KS, Stoker NG, Griffin JR, Grosveld FG, Solomon E. 1985. Identification and characterization of the human type II collagen gene (COL2A1). Proc Natl Acad Sci 82: 2555-2559.

Donaldson CJ, Mathews LS, Vale WW. 1992. Molecular cloning and binding properties of the human type II activin receptor. Biochem Biophys Res Commun 184: 310-316.

Esapa CT, Hough TA, Testori S, Head RA, Crane EA, Chan CP, Evans H, Bassett JH, Tylzanowski P, McNally EG, et al. 2012. A mouse model for spondyloepiphyseal dysplasia congenita with secondary osteoarthritis due to a Col2a1 mutation. J Bone Miner Res 27: 413-428.

Fletcher CDM, Unni K, Mertens F. 2002. Pathology and genetics of tumours of soft tissues and bone. IARC Press, Lyon, France.

Forbes SA, Bindal N, Bamford S, Cole C, Kok CY, Beare D, Jia M, Shepherd R, Leung K, Menzies A, et al. 2011. COSMIC: mining complete cancer genomes in the Catalogue of Somatic Mutations in Cancer. Nucleic Acids Res 39: D945-D950.

Fujimoto A, Totoki Y, Abe T, Boroevich KA, Hosoda F, Nguyen HH, Aoki M, Hosono N, Kubo M, Miya F, et al. 2012. Whole-genome sequencing of liver cancers identifies etiological influences on mutation patterns and recurrent mutations in chromatin regulators. Nat Genet 44: 760-764.

Govindan R, Ding L, Griffith M, Subramanian J, Dees ND, Kanchi KL, Maher CA, Fulton R, Fulton L, Wallis J, et al. 2012. Genomic landscape of nonsmall cell lung cancer in smokers and never-smokers. Cell 150: 11211134.

Harrison CA, Gray PC, Vale WW, Robertson DM. 2005. Antagonists of activin signaling: mechanisms and potential biological applications. Trends Endocrinol Metab 16: 73-78.

Hecht JT, Hogue D, Wang Y, Blanton SH, Wagner M, Strong LC, Raskind W, Hansen MF, Wells D. 1997. Hereditary multiple exostoses (EXT): mutational studies of familial EXT1 cases and EXT-associated malignancies. Am J Hum Genet 60: 80-86.

Hong C, Moorefield KS, Jun P, Aldape KD, Kharbanda S, Phillips HS, Costello JF. 2007. Epigenome scans and cancer genome sequencing converge on WNK2, a kinase-independent suppressor of cell growth. Proc Natl Acad Sci 104: 10974-10979. 
Hopyan S, Gokgoz N, Poon R, Gensure RC, Yu C, Cole WG, Bell RS, Jüppner $\mathrm{H}$, Andrulis IL, Wunder JS, et al. 2002. A mutant PTH/PTHrP type I receptor in enchondromatosis. Nat Genet 30: 306-310.

Hsing AW, Chokkalingam AP. 2006. Prostate cancer epidemiology. Front Biosci 11: 1388-1413.

Koziel L, Kunath M, Kelly OG, Vortkamp A. 2004. Ext1-dependent heparan sulfate regulates the range of Ihh signaling during endochondral ossification. Dev Cell 6: 801-813.

Krzywinski M, Schein J, Birol I, Connors J, Gascoyne R, Horsman D, Jones SJ, Marra MA. 2009. Circos: an information aesthetic for comparative genomics. Genome Res 19: 1639-1645.

Larramendy ML, Tarkkanen M, Valle J, Kivioja AH, Ervasti H, Karaharju E, Salmivalli T, Elomaa I, Knuutila S. 1997. Gains, losses, and amplifications of DNA sequences evaluated by comparative genomic hybridization in chondrosarcomas. Am J Pathol 150: 685-691.

Li H, Durbin R. 2009. Fast and accurate short read alignment with BurrowsWheeler transform. Bioinformatics 25: 1754-1760.

Li H, Handsaker B, Wysoker A, Fennell T, Ruan J, Homer N, Matth G, Abecasis G, Durbin R, 1000 Genome Project Data Processing Subgroup. 2009. The sequence alignment/map format and SAMtools. Bioinformatics 25: 2078-2079.

Matzuk MM, Kumar TR, Bradley A. 1995. Different phenotypes for mice deficient in either activins or activin receptor type II. Nature 374: 356-360.

Moniz S, Veríssimo F, Matos P, Brazão R, Silva E, Kotelevets L, Chastre E, Gespach C, Jordan P. 2007. Protein kinase WNK2 inhibits cell proliferation by negatively modulating the activation of MEK1/ERK1/2. Oncogene 26: 6071-6081.

Nik-Zainal S, Alexandrov LB, Wedge DC, Van Loo P, Greenman CD, Raine K, Jones D, Hinton J, Marshall J, Stebbings LA, et al. 2012. Mutational processes molding the genomes of 21 breast cancers. Cell 149: 979-993.

Nishimura G, Haga N, Kitoh H, Tanaka Y, Sonoda T, Kitamura M, Shirahama S, Itoh T, Nakashima E, Ohashi H, et al. 2005. The phenotypic spectrum of COL2A1 mutations. Hum Mutat 26: 36-43.

Pansuriya TC, van Eijk R, d'Adamo P, van Ruler MA, Kuijjer ML, Oosting J, Cleton-Jansen AM, van Oosterwijk JG, Verbeke SL, Meijer D, et al. 2011. Somatic mosaic IDH1 and IDH2 mutations are associated with enchondroma and spindle cell hemangioma in Ollier disease and Maffucci syndrome. Nat Genet 43: 1256-1261.

Pleasance ED, Stephens PJ, O'Meara S, McBride DJ, Meynert A, Jones D, Lin ML, Beare D, Lau KW, Greenman C, et al. 2010a. A small-cell lung cancer genome with complex signatures of tobacco exposure. Nature 463: 184 190.

Pleasance ED, Cheetham RK, Stephens PJ, McBride DJ, Humphray SJ, Greenman CD, Varela I, Lin ML, Ordóñez GR, Bignell GR, et al. 2010b. A comprehensive catalogue of somatic mutations from a human cancer genome. Nature 463: 191-196.

Puente XS, Pinyol M, Quesada V, Conde L, Ordóñez GR, Villamor N, Escaramis G, Jares P, Beà S, González-Díaz M, et al. 2011. Whole-genome sequencing identifies recurrent mutations in chronic lymphocytic leukaemia. Nature 475: 101-105.

Ren H, Tan ZP, Zhu X, Crosby K, Haack H, Ren JM, Beausoleil S, Moritz A, Innocenti G, Rush J, et al. 2012. Identification of anaplastic lymphoma kinase as a potential therapeutic target in ovarian cancer. Cancer Res 72: 3312-3323.

Rohle D, Popovici-Muller J, Palaskas N, Turcan S, Grommes C, Campos C, Tsoi J, Clark O, Oldrini B, Komisopoulou E, et al. 2013. An inhibitor of mutant IDH1 delays growth and promotes differentiation of glioma cells. Science 340: 626-630.

Schrage YM, Briaire-de Bruijn IH, de Miranda NF, van Oosterwijk J, Taminiau AH, van Wezel T, Hogendoorn PC, Bovée JV. 2009. Kinome profiling of chondrosarcoma reveals SRC-pathway activity and dasatinib as option for treatment. Cancer Res 69: 6216-6222.

Spranger J, Winterpacht A, Zabel B. 1994. The type II collagenopathies: a spectrum of chondrodysplasias. Eur J Pediatr 153: 56-65.

Stratton MR, Campbell PJ, Futreal PA. 2009. The cancer genome. Nature 458: 719-724.

Tarpey PS, Behjati S, Cooke SL, Loo PV, Wedge DC, Pillay N, Marshall J, Meara SO, Davies H, Zainal SN, et al. 2013. Frequent mutation of the major cartilage collagen gene COL2A1 in chondrosarcoma. Nat Genet 45: $923-926$.

Totoki Y, Tatsuno K, Yamamoto S, Arai Y, Hosoda F, Ishikawa S, Tsutsumi S, Sonoda K, Totsuka H, Shirakihara T, et al. 2011. High-resolution characterization of a hepatocellular carcinoma genome. Nat Genet 43: 464-469.

Turcan S, Rohle D, Goenka A, Walsh LA, Fang F, Yilmaz E, Campos C, Fabius AW, Lu C, Ward PS, et al. 2012. IDH1 mutation is sufficient to establish the glioma hypermethylator phenotype. Nature 483: 479483.

Wadayama B, Toguchida J, Yamaguchi T, Sasaki MS, Yamamuro T. 1993. p53 expression and its relationship to DNA alterations in bone and soft tissue sarcomas. Br J Cancer 68: 1134-1139.

Wang YL, Faiola F, Xu M, Pan S, Martinez E. 2008. Human ATAC Is a GCN5/ PCAF-containing acetylase complex with a novel NC2-like histone fold module that interacts with the TATA-binding protein. J Biol Chem 283: 33808-33815.

Whelan J, McTiernan A, Cooper N, Wong YK, Francis M, Vernon S, Strauss SJ. 2012. Incidence and survival of malignant bone sarcomas in England 1979-2007. Int J Cancer 131: E508-E517.

Wuyts W, Van Hul W, De Boulle K, Hendrickx J, Bakker E, Vanhoenacker F, Mollica F, Lüdecke HJ, Sayli BS, Pazzaglia UE, et al. 1998. Mutations in the EXT1 and EXT2 genes in hereditary multiple exostoses. Am J Hum Genet 62: 346-354.

Received May 15, 2013; accepted in revised form June 23, 2014.

1420 Genome Research www.genome.org 


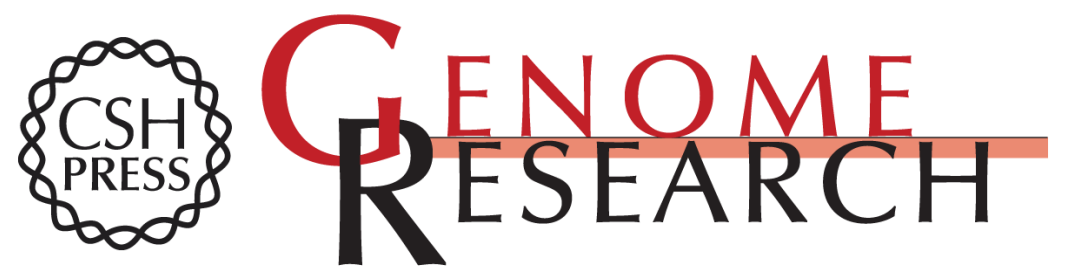

\section{Unique mutation portraits and frequent COL2A1 gene alteration in chondrosarcoma}

Yasushi Totoki, Akihiko Yoshida, Fumie Hosoda, et al.

Genome Res. 2014 24: 1411-1420 originally published online July 14, 2014

Access the most recent version at doi:10.1101/gr.160598.113

Supplemental Material

References

Creative

Commons

License

Email Alerting

Service
http://genome.cshlp.org/content/suppl/2014/07/15/gr.160598.113.DC1

This article cites 43 articles, 6 of which can be accessed free at: http://genome.cshlp.org/content/24/9/1411.full.html\#ref-list-1

This article is distributed exclusively by Cold Spring Harbor Laboratory Press for the first six months after the full-issue publication date (see

http://genome.cshlp.org/site/misc/terms.xhtml). After six months, it is available under a Creative Commons License (Attribution-NonCommercial 4.0 International), as described at http://creativecommons.org/licenses/by-nc/4.0/.

Receive free email alerts when new articles cite this article - sign up in the box at the top right corner of the article or click here.

\section{Affordable, Accurate Sequencing.}

To subscribe to Genome Research go to:

https://genome.cshlp.org/subscriptions 